\title{
Purposive or Accidential! Why Polls Mislead the Public About the Next US President?
}

\section{Fatma Elzahraa Elsayed}

Cairo University, Cairo, Egypt

\begin{abstract}
This study involves the controversial role that public opinion surveys played during the American presidential elections 2016 that has acquired exclamation marks due to the evident conflict between reports of mass media, particularly the private ones, that placed the democratic candidate, Clinton, ahead in the race while results comes directly the opposite.

The study applied "Time for Change" approach and includes three sections; first, the methodology, questions, and objectives. Secondly, the theoretical part and mechanisms of the survey centers, reasons leading to failure in achieving sound results, and the political and economic effects of the newspapers' agendas in guiding the survey results

Thirdly, the last section demonstrates the findings that include: the major reasons that enabled Trump to overcoming the intentional mass media disregard and finally the reasons that made his winning an unexpected shock.
\end{abstract}

Keywords: Public opinion; US presidential elections: Surveys; Time for change approach

\section{Introduction}

Surveys are one of the important tools used by the decision makers in the democratic societies to probe the public opinion trends towards any issue that may concern majority of people. The weight of such tool is even greater when used in predicting some of the future events such as foreseeing the parliamentary or presidential winner. However, what happened in the American presidential elections in November 2016 revealed a fundamental problem in using such tool and relying on its results.

The present study is an attempt to analyze this problem and uncover its reasons. The research relies on some studies that define the reasons that may lead the surveys to fail in predicting the results of elections, the topic is double folded; social and political contexts.

By the political fold we mean that US presidential elections influence not only the American people but also reflects on the overall world issues and events referring to the vision and agenda of the new presidential elect. While the social fold concerns the focus on the public opinion phenomena and methods of measurement and analysis of the reasons that lead to the failure of the surveys that were backed by most of the mass media predicting the winning of the 2016 presidential campaign and what are the mechanisms to be followed to avoid recurrence of such failure in the future.

\section{Methodology}

The problem of the study sets in the evident conflict between the final results of the presidential elections conducted in the US in November 2016 that ended with the victory of the republican candidate Donald Trump and defeat of the democratic candidate Hillary Clinton, and the strong and steady indicators issued by the public opinion surveys conducted by mass media networks, survey centers and newspapers pointing in general to the progress of the democratic candidate that prepared the international public opinion to hearing the victory news of Hillary Clinton as president.
The essential problem in the contradiction seen in the survey results and the election outcome comes from several side problems that may relate to the procedures that might be undertaken towards investigating the accuracy in the style of planning the survey and posing the questions or the style of selecting the public sample that shall answer the questions of the survey and the direct and indirect communication means and if such sample ideally represents the study population in order to be credible when applied to the whole society, and what are the available limits of accuracy in the field or electronic work as far as concerned the collection of data, objective analysis, its exposure in transparency, completeness, integrity and clarity without explanations or interpretations that smear the facts due to biases of some parties that are interested in showing specific facts and hiding defacing or marginalizing other facts and consequently misleading the public opinion. The study questions are:

RQ1: What is the importance of the surveys conducted by public opinion measurement centers in reading the American political context?

RQ2: What are the mechanisms that control public opinion survey work?

RQ3: What are the reasons that may lead to failure of the surveys in predicting accurate results? This study aims at achieving four main

${ }^{*}$ Corresponding author: Fatma Elzahraa Elsayed, Cairo University. Cairo, Egypt E-mail: zahraafat@cu.edu.eg

Received May 09, 2017; Accepted September 14, 2017; Published September 18, 2017

Citation: Elsayed FE (2017) Purposive or Accidential! Why Polls Mislead the Public About the Next US President? J Mass Communicat Journalism 7: 345. doi: 10.4172/2165-7912.1000345

Copyright: @ 2017 Elsayed FE. This is an open-access article distributed under the terms of the Creative Commons Attribution License, which permits unrestricted use, distribution, and reproduction in any medium, provided the original author and source are credited. 
objectives: First: identify the importance of public opinion survey in society in general and particularly in the American political context. Second: discover the reasons behind the failure of the surveys in predicting accurate results. Third: analyze the mechanisms controlling the survey centers and its role in predicting the winner in the American presidential race. Finally: evaluate the relationship between the survey centers and the mass media in presenting non-realistic trends about the public opinion during the presidential elections.

The study focused on two main axes that formed the research population that when qualitatively analyzed may provide answers to the questions of the study, the axes are: all the articles about the presidential elections during the year preceding the elections in the New York Times and on the same subject in the Washington Post directly after the elections.

Sample of speeches of the presidential candidates during the presidential race in various states. (20 speeches, 10 of Clinton and 10 of Trump including the ones that they declared acceptance of their parties' nominations to run for US presidency.

\section{Theoretical Approach}

Time for Change model [1] considers the practical possibility of predicting the winner in the American presidential elections even without relying on the surveys conducted by the public opinion centers and it is founded on three basic conditions that must be determined namely (Figure 1).

The application of this model means that the American elector is voting for the parties rather for the persons. In the year 2000 an $80 \%$ of those satisfied of Bill Clinton's performance voted for Al Gore while $90 \%$ of those not-satisfied of Bill Clinton's performance voted for George W Bush Jr that is the American presidential elections is in somehow a poll on the extent of satisfaction of the Americans towards the performance of the party of the incumbent president.

The popularity of the president is being measured whereby the rate of satisfaction towards his performance at the middle of the elections year. The general status of the economy is being measure at the second quarter of the elections year based on the annual growth of GDP. Often, such economic indicators have a great influence on the electors' votes.

Finally, the term of the party to which belongs the president in running the White House and whether there exists a chance to

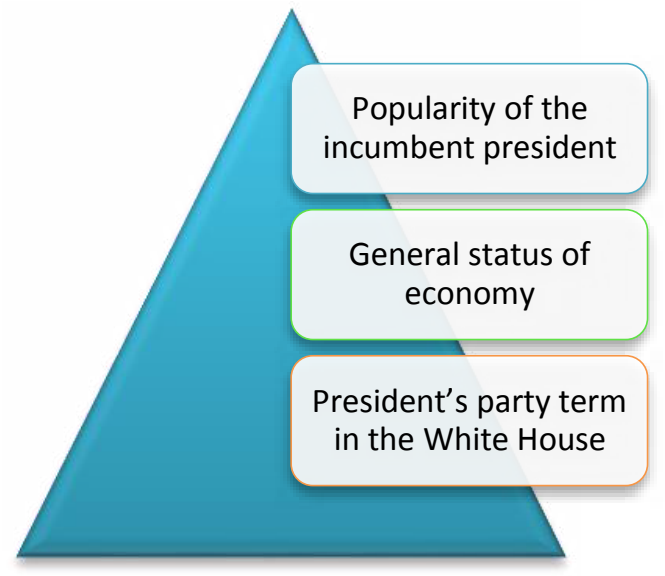

Figure 1: the public opinion centers and it is founded on three basic conditions. grant it a second mandate in case of satisfaction towards the party's performance or otherwise it's time for change and chose the candidate of the competing party.

\section{Role of the opinion survey in the American elections}

Some of the public opinion surveys' results conducted during presidential elections helped the candidates to take some decisions regarding management of their campaigns.

This was clear in 2008 elections where the early survey results revealed the concern of the electors of the limited experience of the democratic candidate Obama in the field of foreign policy while uncovered the concern towards the old age of the republican candidate John McKean. Both candidates have responded with such results as Obama appointed Joseph Biden who has over 30 years of experience in the foreign affairs as his deputy and McKean was poised to appoint Sara Palin, the unknown Alaska governor who was of young age of 44 years and being the first woman to occupy such a position during the history of the United State.

The 2008 elections' results revealed the reliability of the prognostics of the surveys where the early comers have decided early to support the democratic candidate while the two candidates shared votes of late comers at a percentage of $53 \%$ for the democrat and $46 \%$ for the republican in the final elections.

These results were compatible remarkably the survey results that the late comers' votes consolidated the early votes and not adding new votes to either candidate.

However, the 2016 elections resulted revealed the contrary of the survey prognostics conducted by various mass media institutions. This situation poses several questions that this study tries to answer. In a statement about the position of the public opinion survey inside the American society, one of the field studies published in one of the most important specialized scientific periodicals in the public opinion in the United States which is the international magazine on public opinion researches, it indicated that most of the respondents feel that the survey do not have any influence on them but rather have on the others (in a practical representation of the third party who is already influenced by the content of the mass media but does not uncover itself), the researchers concluded from this study that the opinions of the respondents about the survey and its attendants have to a great extent been influenced by the state of non-confidence in the mass media performance in general [2].

Another study defined the effect of publishing public opinion surveys in the presidential pre-elections stage on the behavior of the citizens in acquiring information on the presidential candidates where the decision making in this stage is linked to the experience of being exposed to the published survey results in the various internet sites [3]. It has been concluded that being exposed to the survey results is an important mediator factor between the behavior of seeking information as a subordinate variable and the decision of selecting ascertain candidate as an independent variable.

The study considered that conducting surveys in this context embodies the "bandwagon effect" which is apparent during the election time when the people vote for the one poised to win in their desire to be on the winning side.

One of the experimental studies conducted on the effect of exposure to the surveys on the electoral decision in 1992 during the George Bush sr. and Bill Clinton, where the students were set in to groups and their 
opinions polled about their intentions to vote for one candidate, then expose only one group to the results of the survey that confirmed the higher winning chances of Clinton. They were then asked to express their intentions once again where a high proportion of those who first chose Bosh before being exposed to the survey results have changed vies and chose Clinton in the second time [4].

\section{Mechanisms of public opinion surveying in American context}

It's well known in the field of public opinion studies that there are two major modes for conducting the public opinion surveys. Such classification depends on the time variable as determinant of the style and steps in conducting the survey.

The first mode is when the available time for conducting the survey is limited and the population under study is huge which is applicable to those surveys conducted at the time of elections. This mode is characterized by volatility and speed that may violate in most cases the accuracy, comprehensiveness, and soundness of the results. The second mode is the profound surveys that need extended time and often observe accuracy in analyzing results. The later profound mode of surveys is unavailable before the elections.

Gallup Inc. defines clearly the scientific method that it adopts in the surveys. It depends on the daily tracking survey mechanism that Gallup started in 2008 unprecedented by any other institution. It undertakes two parallel surveys daily each probing the opinions of 500 persons with a max total of 1000 person a day.

The first survey deals with the United States general affairs and is called the US daily while the second handles the well-being and health and is called well-being index Gallup health. That means 15000 persons are probed in each survey with a total of 175000 persons a year as the center works seven days a week and 350 days a year. Such surveys enable Gallup to check wide areas and intersection of demographic data measured daily. Gallup can add some questions to these surveys to be linked to temporary events such as election seasons or the on-going global events.

Gallup collects data by telephone and mobile lines combined in a system called Dual-Frame design and using the random call based on samples purchased from some specialized institutions such as Survey Sampling International (SSI).

In a study prepared by prof. Allan J. Lichtman, a historian in the University of Washington, with whom the New York Times had a special interview where he predicted a year ago that Donald Trump shall win the presidential race [5].

He based his prediction on a model he designed in 1981 in collaboration with a specialized Russian seismologist. Lichtman explains his model as being linked to what he called: the pragmatic voting, so when the voters are satisfied of the incumbent party performance, most likely they shall give his candidate additional 4 years' mandate in the White House, but if they not satisfied, then the chances of the competing candidate in winning the presidential race is higher.

Consequently, the selection of the candidate does not depend on what his campaign has conducted of debates, speeches, advertisement, promises or recommendations from trusted parties, but depends on the performance level of the party holding the management of the White House.

The model includes 13 criteria that maybe applied on the party holding the White House, and if the party succeeds in scoring in these points together, then it's evident that its candidate shall with the presidential race and shall be voted 4 years in the White Hose, and if it fails in scoring in these points, it means that absolutely that the voting shall go to the opponent. These points are as follows: party representation, fight, simultaneity, third party, short-term economic stance, long-term economic stance, political change, social anxiety, scandals, military/ external failure, military/ internal failure, incumbent candidate charisma and opponent candidate charisma.

The relative weight of each point is being evaluated whereby certain code to be later calculated by a mathematical equation the resultant of which shall be determinant of which candidate shall win the presidential elections. Chart No. 2 illustrates the result of the equation that has been calculated showing sheer supremacy or the Republican Party candidate (50.3\%) (Figure 2).

One of the studies confirm that the use of meta-analysis is the style the survey centers must adopt to predict the presidential elections. While the traditional analysis of the surveys depends on the single scanning to obtain the results, the meta-analysis tends to collect all the scans together through an extended time, example: all the states in one day. (Wang, S. S.H. 2015). Such analysis is considered as an electoral thermometer to measure the rise and fall of the performance of electoral campaigns in achieving its objective in the various states within the campaign of one candidate (Figure 3 ).

\section{Why polls failed?}

Public opinion surveys should observe some procedural and methodological conditions that participate in the safety and soundness of the steps taken to measure the different type of public opinion.

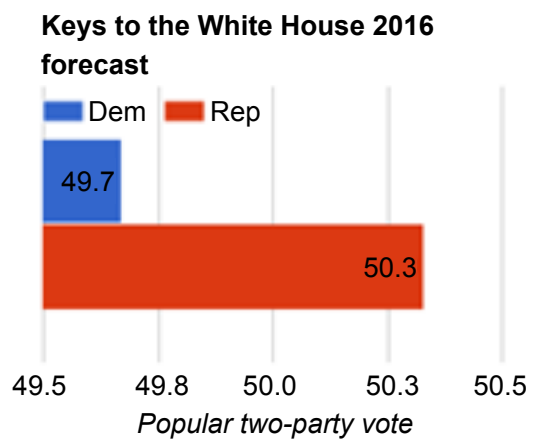

Figure 2: Keys to the white house 2016 forecast.

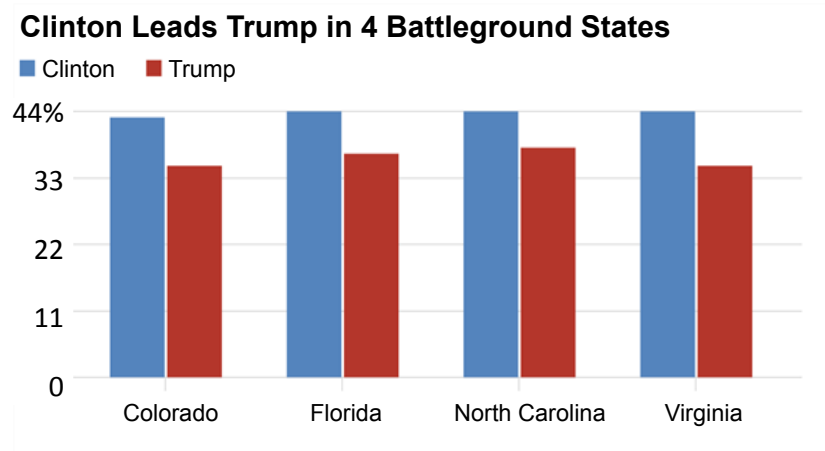

NBC News/WSJ/Maris polls, July 5-11

Figure 3: Clinton leads trump in 4 battleground states. 
Among which: accuracy in preparing the investigation journal or the form questions according to the sample selection, accuracy in the field activity, accuracy in updating, tabulating, analysis and interpretation of results.

In addition to the fact that the questions should not be worded in such a way to suggest specific answers and that the selections available to the respondent include as much as possible all the eventual answers and are diversified among the open, closed and semi-closed ends.

There are some studies conducted in view of reaching the most active formula in measuring the American public opinion to define the variables to be included in the measurement equation to obtain the most accurate possible predictions of the public opinion trends for each state particularly during the presidential elections [6]. Its results confirmed that relying on various active multi-dimensional models is better in predicting the results from the Uni-dimensional models.

The study suggests the dimensions to be included in the model by four as follows:

The economic stance of the state (measured by its contribution in the GNP).

Relative weight of the candidates challenging strength.

The total voting strength of the state.

Political momentum of the state allegiance to the party.

Another study suggested what it called the micro-model in surveying the public opinion about its prognostics of victory of a presidential candidate in contrast to what is often employed of the macro-models that rely on a linear regression equation of a series of time date for number of national political and economic variables [7].

The alternative model confirms the possibility of relying mainly on the personal survey results that are being conducted directly as field scans on the population members such as that conducted by Gallup center. The individual trends in such surveys may be divided in to categories: intentional voting category and predictive voting category.

The intentions category relies basically on the final surveys conducted by Gallup center right before the presidential elections that is characterized by high accuracy with eventual errors. Since 1948 till now the center had failed only twice in a total of thirteen times in predicting the outcome of presidential elections.

While the voting predictions rely on two mechanisms: the first mechanism is the indicators of the politics stock market speculations and the second mechanism represents the direct field scans. In applying this model, it becomes clear that the electors' predictions of the winner in presidential race do not follow a random model but on the contrary the electors can correctly predict the upcoming presidential elect at the rate of $71 \%$.

Among the reasons that led the survey centers to fail in predicting the public opinion trends accurately is the popularity of the "Silent Vote" phenomenon that seems to have widened significantly prior to November 2016 elections [8]. Silent vote means that the respondent denies giving his opinion about his preferred candidate. This denial is not in the interest of the survey centers as they cannot include it among the surveyed numbers and have no idea about his orientation. Some analysts have indicated that those who denied giving their opinions support Trump. That means that there is huge number of electors not included in the surveys that shall undoubtedly lead to contrast of its results with the actual election results that included opinions who denied participating in the survey.

The (Spiral of Silence) theory can interpret as well the silent vote phenomenon [9]. By looking into the extravagant promotion and mass media and advertisement focus in Clinton campaign in polishing the profile of its candidate and convince the public, and in contrast trying to vilify the reputation of the opponent and expose its drawbacks (but without effective interrogative effort challenging his reputation except for accusations and suspect testimonies), the having different views and those not convinced of all such attempts enter in a state of silence and prefer to keep their opinion for themselves until the coming of the proper time of disclosing it in the electoral commission to dodge social denial and critique. New York Times refers to what it called "the Bradley effect" that appeared in 1982 when the white republican governor of California opposed the black democratic candidate Tom Bradley who skimmed unexpected defeat incompatible with the surveys that placed him ahead in the race.

The reason behind this was lots of republicans denied recognizing that they will give their votes to a black candidate.

In addition to the foregoing, the increasing dependence on the internet as means of communication with the public makes it easier place for surveys without committing to any scientific or systematic conditions in verifying the soundness of results and without taking organized procedures in selecting a sound sample to be valid as basis for generalization, but depends basically on the readiness of any visitor to participate in the survey.

We can say that at the time the official surveys were showing Clinton overrun Trump with a comfortable margin, lots of the republican internet sites were showing Trump overrunning Clinton with a big gap even in its evaluation of both candidates during the debates [10].

One of the studies conducted by Five Thirty Eight Center specialized in surveys since 2008 indicated that one the reasons that led to the failure of the surveys in predicting the results of November 2016 elections was the reliance on indecisive variables in determining the opinion such as: income, party allegiance, geographic location or ethnicity, all combined were not decisive variables in the elections in contract to the education level which undoubtedly was the governing and decisive variable [11]. This was what made the difference between the democrats' victory in 2012 and their defeat in 2016 for number of reasons.

Trump has addressed a severe critique to the elite intellectuals of liberal drive majority of who are affiliated to the democratic party and many work in the mass media and hold high university degrees and believe in the principles of liberalism and cultural diversification. This placed such category in general in a state of primordial animosity with Trump and gives their votes to Hillary. One of the studies conducted in 2015 about the university journalism in the United States undiscovered a clear bias in the opinion pages in profit of the democrats and against the republicans while covering the news with more objectivity [12]

University education promotes intense dealing with ethnic minorities and different origins that leads the university goers to respect the culture of the other, while individuals who did not follow the university even having high income are more responsive to the exclusive speech giving no weight to the different other and more prone to adopt violent measures against it without remorse.

The level of education is closely linked to the habits of exposure to the mass media, so that the less educated individuals often prefer the 
$\mathrm{TV}$, however, the severe decline in the credibility of this means pushes them to seek the content they like in the internet that often support the views they believe in already, and Trump succeeded to communicate extensively with his supporters via the social mass media to make up for the traditional mass media disregarding him.

Trump speech was rich in its sensational and emotional expressions, which are all suitable means to convince the less educated categories and affect them. It was natural that he shall be their candidate and win their votes. In addition to the foregoing, what is shown in advertisement and promotion regarding the survey results is what the recipient admit as the real reflection of the public opinion trends, while the reality is something else. What is being shown is not what is all about and there are surveys conducted mid-July 2016 that showed a clear progress of Trump over Clinton in the decisive states of Florida, Pennsylvania, and Ohio but it has never been focused on, highlighted, and followed [13].

The results of such surveys indicated that the citizens of these states desire making radical changes in the politics and economy and view that Trump the most capable and positioned to do it. It also uncovered their great anger towards the trade agreements that jeopardized the interests of the United States and considered Trump the most qualified person to eradicate terrorism.

There is an important study that indicates that one of the reasons behind the failure of the surveys in predicting accurate results is that many of the centers conducting the surveys does not declare with transparency the measures they adopted in carrying out the survey and may not be sincere in describing the steps they have taken particularly in the absence of two important elements: the control and benchmarking [14]. The fact is that there is no accountability or control or any kind on the actions of the public opinion centers in spite that its works is not less important than that of the mass media. Further, there exists no professional benchmarking in the public opinion industry that may be taken as criteria in judging the quality of the surveys.

Finally, the findings of one study confirm that the focusing of some surveys to uncover the intents of the electors may increase its failure in predicting accurate results and that it's better to focus on the expectations of the electors [15]. It added that 193 out of 217 surveys conducted between 1932 and 2012 with the aim of foreseeing the winner in elections have succeeded in their aims as they only focused on the elector expectations with simple questions, while the more complicated surveys that relied on several indicators among which the voting intentions besides the quantitative models, forecasts stock exchange and expert judgment.

\begin{tabular}{|c|c|c|c|c|c|c|c|}
\hline State & E.V & NYT & 538 & DK & Huffpost & PW & PEC \\
\hline New Hampshire & 4 & $87 \%$ Dem. & 76 \% Dem. & 91\% Dem. & $98 \%$ Dem. & $93 \%$ Dem. & $93 \%$ Dem. \\
\hline Pennsylvania & 20 & 87\% Dem. & 80\% Dem. & 87\% Dem. & 98\% Dem. & 90\% Dem. & 89\% Dem. \\
\hline Michigan & 16 & 87\% Dem. & $82 \%$ Dem. & 97\% Dem. & 95\% Dem. & 94\% Dem. & 84\% Dem. \\
\hline Colorado & 9 & 85\% Dem. & 78\% Dem. & 86\% Dem. & $98 \%$ Dem. & 92\% Dem. & 81\% Dem. \\
\hline Wisconsin & 10 & 80\% Dem. & 82\% Dem. & 91\% Dem. & 93\% Dem. & 92\% Dem. & 69\% Dem. \\
\hline Florida & 29 & 68\% Dem. & 63\% Dem. & 64\% Dem. & $90 \%$ Dem. & 72\% Dem. & 69\% Dem. \\
\hline Nevada & 6 & 66\% Dem. & 63\% Dem. & $54 \%$ Dem. & $50 \%$ Dem. & 75\% Dem. & 65\% Dem. \\
\hline North Carolina & 15 & $60 \%$ Dem. & $59 \%$ Dem. & $60 \%$ Dem. & $77 \%$ Dem. & 64\% Dem. & 69\% Dem. \\
\hline Ohio & 18 & $54 \%$ Dem. & $52 \%$ Dem. & 75\% Rep. & 57\% Rep. & $52 \%$ Rep. & $60 \%$ Rep. \\
\hline Lowa & 6 & $57 \%$ Rep. & $53 \%$ Rep. & 87\% Rep. & 84\% Rep. & 57\% Rep. & $60 \%$ Rep. \\
\hline Arizona & 11 & 79\% Rep. & $62 \%$ Rep. & 92\% Rep. & 88\% Rep. & 83\% Rep. & 69\% Rep. \\
\hline Georgia & 16 & 82\% Rep. & 77\% Rep. & 90\% Rep. & 97\% Rep. & 90\% Rep. & 99\% Rep. \\
\hline South Carolina & 9 & 90\% Rep. & 89\% Rep. & $>99 \%$ Rep. & 98\% Rep. & 97\% Rep. & 89\% Rep. \\
\hline Missouri & 10 & 93\% Rep. & 85\% Rep. & $>99 \%$ Rep. & 99\% Rep. & 95\% Rep. & 99\% Rep. \\
\hline
\end{tabular}

Table 1: The surveys conducted by specialised media.

\section{Results}

We have four cases of opinion surveys conducted by various mass media that we shall bring under scrutiny and critique in order to ultimately formulate a set of conclusions that if assimilated shall interpret clearly the reasons behind the failure of the surveys in predicting the presidential elections results.

First, we should indicate that there are three challenges that faced the process of surveying the potential electors namely the severe decrease in landlines which is the essential tool besides mobile lines in view of correct sampling. Second, the increasing number of the citizens unwilling to participate in surveys. Third, the unclear position of the swing states particularly North Carolina and Ohio the votes of which is important for the candidate to win the elections. The results in these states remain indecisive till end of the race making early survey not precise [16].

The survey published by New York Times one week before the election, Table 1 where it held a comparison between a number of surveys conducted by specialized mass media namely: Princeton Election Consortium, Daily Kos, Pew, Huffington Post, Five Thirty Eight and New York Times itself where each has estimated its predictions in 14 states representing a higher quota in the electoral college denoting the support weight for each party in blue gradient for the democrats and red gradient for the republicans and yellow for those undecided states which is Florida, North Carolina, Nevada, Ohio and Iowa, the survey did not explain what might happen if such states has opted for Trump a situation which should have reverse the survey results, instead it has simple excluded such possibility with explanation. The survey has also considered that the states of Pennsylvania, Michigan and Wisconsin are concluded for the democrats in contrast to the final election results.

The survey published by Five Thirty Eight Inc. and predicted the victory of Clinton in the popular voting and in the electoral college vote, Figure 4, that did not explain absolutely the position of the swing states and divided the states between the republican and democratic parties, which resulted in gross mistakes in generalization and then in predicting the result, as the survey reckoned the states of Wisconsin, Michigan, Florida and North Carolina as democratic contrary to the final results where Trump was the winner [11].

The results of the surveys conducted by Survey Monkey Inc. in collaboration with NBC news network (Figure 5) on a sample of 40816 adult expected to vote, which is an acknowledgement from the surveyor that this sample is "not probable" and consequently its "non-scientific" sample which should not be given that weight by the mass media and 

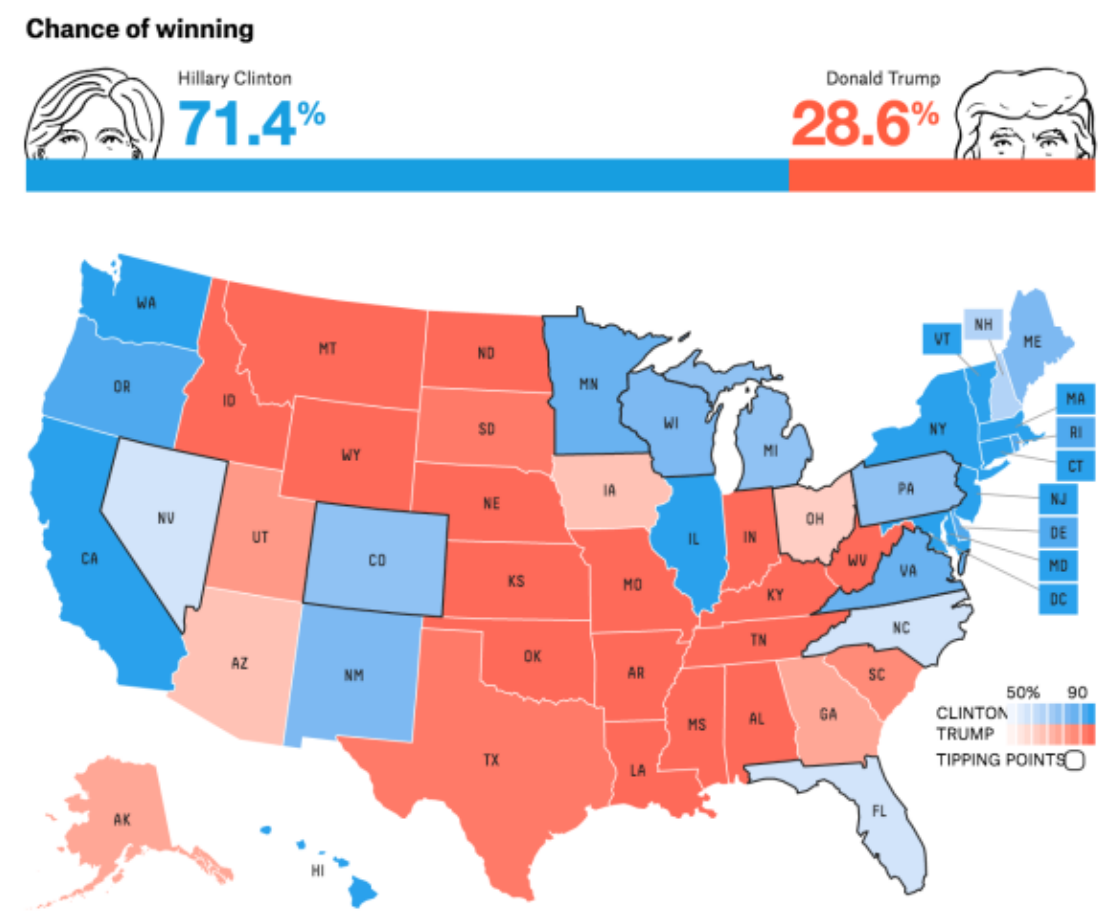

Electoral votes

Popular vote

\begin{tabular}{|c|c|c|c|}
\hline - Hillary Clinton & 302.2 & E Hillary Clinton & $48.5 \%$ \\
\hline Donald Trump & 235.0 & Donald Trump & $44.9 \%$ \\
\hline Evan McMullin & 0.8 & Eary Johnson & $5.0 \%$ \\
\hline Wary Johnson & 0.0 & = Other & $1.6 \%$ \\
\hline
\end{tabular}

Figure 4: Controversial comparison between two types of voting in the US elections.

\section{FBI Comey Letter}

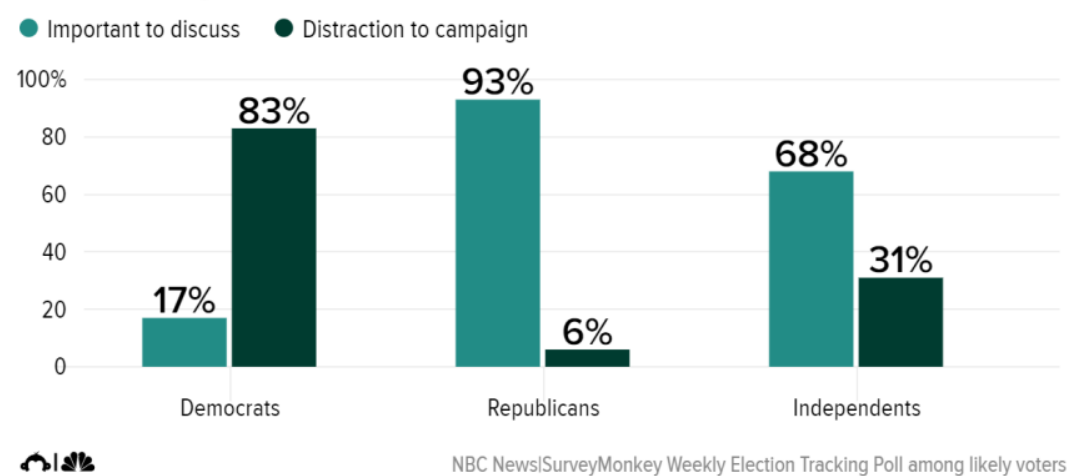

Figure 5: Remarkable effect of the FBI letter on the independents.

deliver its results as for granted as the answer of the probable voter is $50 \%$ doubtful and it should have been included in both cases, the case if it goes to voting and if it abstains from voting [17].

Being satisfied with the superficial opinion without heeding the reverse probabilities although powerful would result in misleading result and that's what happened in most of the surveys that showed superiority of Clinton against its opponent during one and half month prior to the presidential elections that have been published simultaneously with the other two surveys, Figure 5 shows voters' trends about the importance of FBI director report about Clinton emails and Figure 6 shows the clear decline of the percentage of the voter's satisfaction after the first debate, which decline more or less persisted after the second and third debates, noting that decrease in the number of undecided who possibly went in favor of Trump, which situation was not handled by the mass media that focused only on Clinton superiority. 


\section{Who won the debate?}

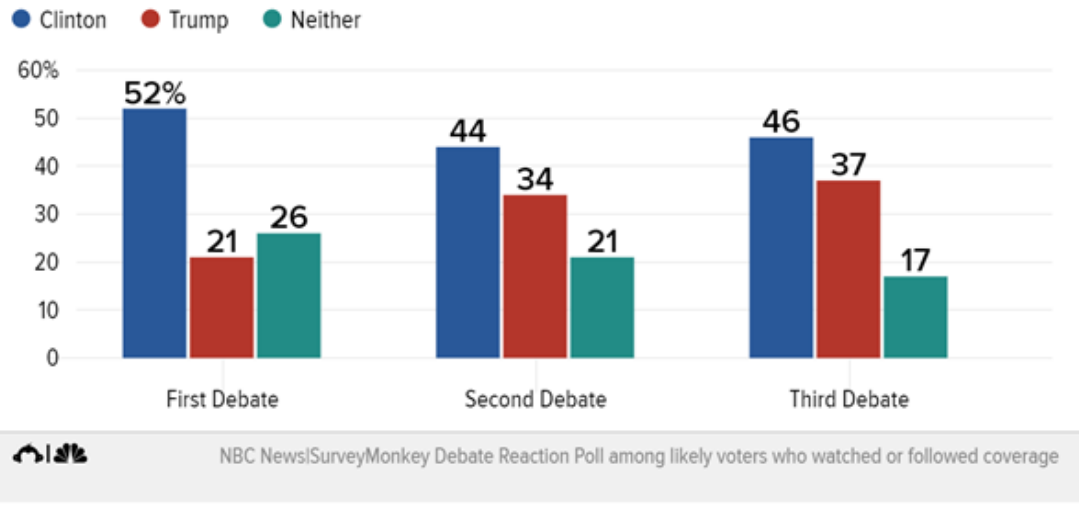

Figure 6: Polls ignored Trump's improvement and focused on Hillary's consistent superiority.

\begin{tabular}{|c|c|c|c|c|}
\hline & $\begin{array}{c}\text { High importance to vote } \\
{ }^{\wedge}\end{array}$ & Prefer trump on issue & Prefer Clinton on issue & Advantage \\
\hline The economy & 92 & 53 & 43 & Trump +10 \\
\hline Employment and jobs & 89 & 52 & 45 & Trump +7 \\
\hline Terrorism and national security & 87 & 50 & 46 & Trump +4 \\
\hline The federal budget deficit & 78 & 57 & 39 & Trump +18 \\
\hline Taxes & 71 & 52 & 44 & Trump +8 \\
\hline $\begin{array}{l}\text { The size and efficiency of the } \\
\text { federal government }\end{array}$ & 64 & 55 & 41 & Trump +14 \\
\hline Gun policy & 63 & 50 & 45 & Trump +5 \\
\hline $\begin{array}{l}\text { Government regulation of wall } \\
\text { street and banks }\end{array}$ & 59 & 53 & 42 & Trump +11 \\
\hline
\end{tabular}

Table 2: Gallups survey demonstrates Trump's progression in the most critical issues of the US citizen.

In an interview with Nate Cohn, an insider who led the election prognostics during the presidential campaign, with New York news declared that there's almost intentional overlooking of tracking the decline in Clinton's popularity over the last two months preceding the elections particularly in the Midwest known as "Rust Belt" that include the states of Michigan, Pennsylvania, Ohio and Wisconsin where lots of insiders reckoned it on the democratic side, neglecting that any state of both urban and rural facet should be given an equal importance, the error resided in focusing on the urban side and disregarding the rural one, while in reality the electoral weight of the lower educated (Figure 6). White mass of the working class was much higher than the mass of the higher educated class present in the cities [18].

The survey on electors' opinion on James Komy's - FBI directorreport showed that two thirds of the independents (non-belonging to either party) who could be seen as "control group" consider that the report is important and of foundation that might not be overlooked or dealt with recklessly as being a diverting factor of Clinton campaign, which opinion was adopted by the democrats, while this issue should have been handled with more transparency, interest and concern to uncover the full truth before the public opinion. It seems that the email issue was the iron wedge that was steadily hammered by Trump has caused s profound cleft that kept growing till it led to a partial destruction of the Clinton camp on one side and on the other side paved the way for those who did not make up their minds yet to opt for selecting Trump. A percentage not to be neglected (17\%) of the democrats view that it's important to open a serious discussion on that issue, however, the time was too tight for Clinton to narrow this gap with the elections on the doorsteps.
George Box, one of the statisticians who participated in designing the survey forms, confirms that there have been mistakes committed by everyone, the main reason was neglecting the facts found in the survey databases since 1980 which indicating that among 248 opinion survey conducted in the United States over the last one hundred and fifty days ahead of the elections, 49 of which the gap between the democratic and republican candidates was 10 points, in only three cases the final results followed the surveys, and each time the same scenario occurs, where the democratic candidate seem to dominate in one state but finally the republican candidate wins.

Among the defects smearing the national surveys, as per results given in fig. no. 3 , is that they were relatively right on the popular voting level in the states in general, but it was better to survey the opinions in the demographically similar states, because the voting was done following the mechanism of similar population groups in the various stats and not on the state level apart for the other states [11].

The white rural working class of lower education was higher than white of higher education in the urban regions who recorded unexpected low level, the same happened in all states, and the density of voting Latinos and blacks decreased in all the states that made Clinton losing states she should had win to gather more votes in the electoral college.

An example of the erroneous predictions it what has done Drew Linzer, Daily Kos website founder on election prognostics whose predictions were the cornerstone of the New York Times in foreseeing Clinton's victory, Table 1, when it counted the votes that Clinton shall 


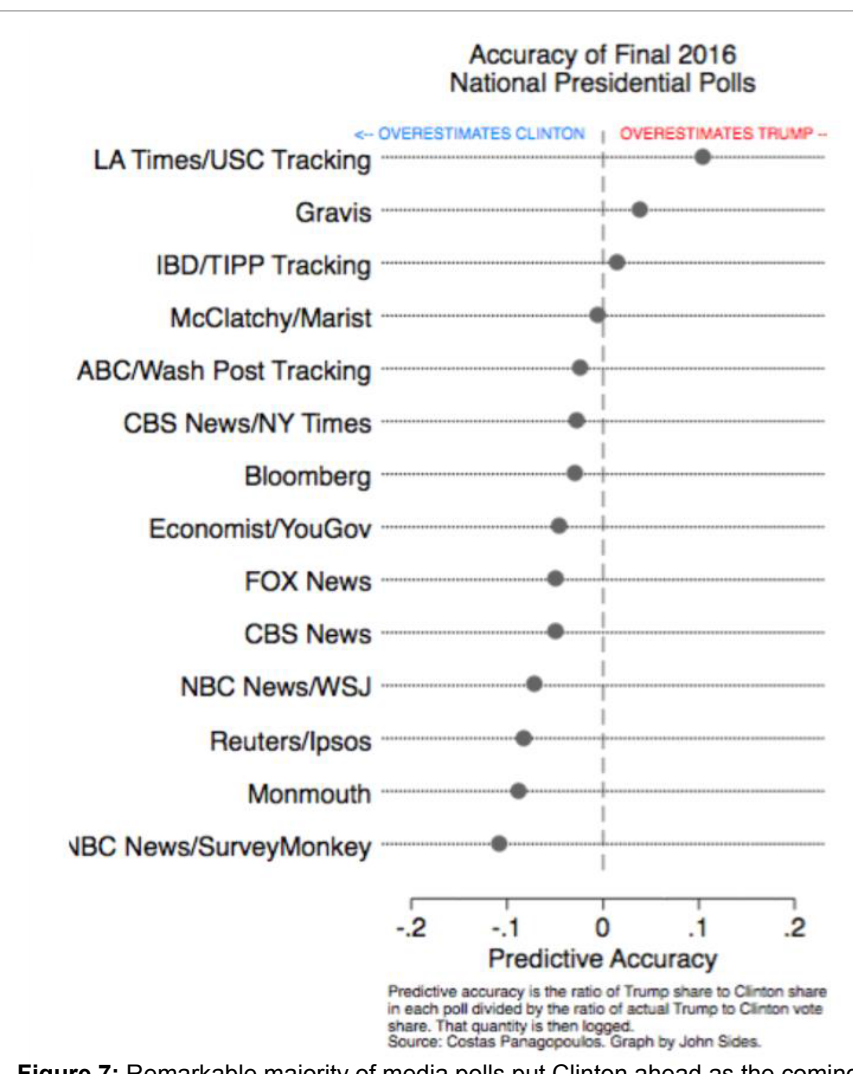

Figure 7: Remarkable majority of media polls put Clinton ahead as the coming US president.

win in the electoral college according to the popular voting expected for the democrats in each state, giving Clinton 323 votes against 215 for Trump, however, due to inaccuracy in calculating the real number of the voters, this model failed in predicting the sound results and fantasized Clinton wining the president race [19].

In a survey conducted by Gallup to probe the voters opinion about the preferences of the presidential candidate more capable of dealing with the vital files of the American society, as shown in Table 2, conducted in the period from 18-25 May 2016 using phone calls with a sample of 1530 adult individual in 50 states with an error margin of \pm 3 , the survey included 17 issues of general interest to the Americans including: economy, unemployment, terrorism, national security, education, healthcare, immigration, wealth distribution, homosexuality, atmospheric changes and minorities circumstances, where the results showed that Clinton overtook Trump in all issues that the voters view her more competent to deal with (nine issues) while Trump dominated in eight other issues: budget deficit, taxes, federal government efficiency, arms policy, rules governing banks and Wall Street [20].

The surveyor did not explain that the predominance of Trump in the three issues of economy, unemployment and social security is enough strongly favor his to win the elections, as they know from their experience that these files are of the most vital for the American elector than the others in the presidential elections, no matter the predominance rate of the opponent, that's to say that early and well before the eruption of the email scandal of Clinton, the electors believed that Trump is better in handling the most important issues, which was not center of interest of the survey interpretations while the focus was on the overall predominance of Clinton in the issues combined, this has contributed in making the surveys' results misleading.

Even in reviewing the table attached to the survey which contained number of issues where Trump dominates, we found that it's 9 issues against only 8 for Clinton, which is contrary to what is stated in the report. The least to be said about the situation is inaccurate and misleading (Figure 7).

\section{Conclusion}

Mass media followers should know that the surveys are merely tools that may be helpful to come up with indicators about the orientation of the public opinion towards a specific case but not a tool to rely on in prediction. When it describes the chances of one candidate being better than another candidate it does not mean that the preferred candidate shall win $100 \%$, giving more weight to the survey makes it misleading.

All surveys without exception bear margin of statistical error the bigger the smaller the sample. Seen the demographic composition of Clinton supporters from the ethnical minorities, immigrants, and homosexual, it becomes clear that the surveys that relied on samples of their own were more prone to error that others, where the surveys did not provide explanations based on considering such percentage in case of effect on the results.

All surveys that gave preference to Clinton in a greater number of states and consequently the priority in the popular voting did not focus on the fact that the popular voting alone does not guarantee wining the presidential race and this happened once and again in previous presidential elections. The determinant is the votes of the Electoral College where the winner should obtain more than 270 votes, and persisted on the popular preference of Clinton being a guarantee for her victory which is not true.

All surveys without exception did not heed the stance of the undetermined states for a specific candidate, in spite of the fact that the percentage of these states is higher than any previous elections $(12 \%$ of the states combined). While if given the appropriate weight with somehow objectivity, it would have put Trump on top if the decide in his favor, this is what happened.

The surveys depend increasingly on the internet as medium for counting votes and proportions, there is up to now no consensus among the specialists over the best practice that achieves the condition of probability which is the cornerstone of accuracy in any survey to be conducted, this proposes that the success achieved by some of these surveys in predicting the results is haphazard and not by way of good scientific design.

Most of the surveys conducted by the great mass media (such as New York Times) is carried out within one week on a sample of more or less 1500 adult individual who declare being registered on the election databases, using both English and Spanish languages, where computer is used to select a random sample from a list including 82 thousand active subscriber in the landlines, submitted by Horsham marketing systems, and the error margin in such small samples is big, reason for which and in view of compensating such error contact is established with the cellular phone subscribers.

The insiders acknowledge that some of the respondents misunderstand sometimes the questions they hear over the phone and consequently the error margin of response over the phone is unlimited and may not be measurable. 
Citation: Elsayed FE (2017) Purposive or Accidential! Why Polls Mislead the Public About the Next US President? J Mass Communicat Journalism 7: 345. doi: 10.4172/2165-7912.1000345

Page 9 of 9

The Washington Post newspaper published a report the morning following the election results expressing the extent of disappointment of the Rust Belt inhabitant towards the promises of the democrats that were huge [21].

A state such as Pennsylvania kept voting for the democrats since 1992, but decided this time to follow Trumps promises in creating job positions and improvement of the trade agreements conditions that the United States entered during the democratic mandate and was a fiasco, and gave their vote to Trump who won with a gap of 68000 vote. The same happened in the states of Ohio and Michigan where Trump swept with a gap of 12000 vote, even in the state of Iowa that voted twice for Obama preferred to vote for Trump this time.

The Washington Post published a report contained a classification made by the political scientist Costas Panagopoulos in tabulating the centers and mass media that conducted surveys predicting the victory of one candidate in the presidential elections.

The classification was based on the percentage given by each survey to the candidate divided by the actual percentage of the elections, the outcome was charted showing the extent of bias of each survey in favor of one candidate, the Los Angeles Times and USC poll were the more biased in favor of Trump putting him on the top during all the periods preceding the elections while Survey Monkey Inc. with NBC News were more biased in favor of Clinton putting her on the top in almost all their surveys [22]. While the entity that has been nearest to accuracy was McClatchy/Marist and IBD/TIPP.

\section{References}

1. Abramowitz A (2008) Forecasting the 2008 Presidential Election with the Timefor-Change Model. Political Science and Politics 41: 691-695.

2. Price V, Stroud N (2005) Public attitudes toward polls: evidence from the 2000 US presidential election. International Journal of Public Opinion Research 18: 393-421.

3. Jason R, Shane PS, Patrick F, Blake A (2015) An experimental analysis of the impact of campaign polls on electoral information seeking. Electoral Studies, OPINION-POLICY NEXUS

4. Morwitz V, Pluzinski C (1996) Do Polls Reflect Opinions or Do Opinions Reflect Polls? The Impact of Political Polling on Voters' Expectations, Preferences, and Behavior. Journal of Consumer Research 23: 53-65.
5. Schuessler J (2016) Yes, he thought Trump would win, No, he didn't use hard data. The NYT

6. Stambrough S, Thorson G (1999) Toward stability in presidential forecasting : the development of multiple indicator model. International Journal of Forecasting 15: 143-152.

7. Lewis-Beck M, Tien C (1999) Voters as forecasters: a micromodel of election prediction. International Journal of Forecasting 15: 175 -184.

8. Hunt AR (2016) Silence may be good news for Trump. Bloomberg View

9. Neumann EN (1977) Turbulences in the climate of opinion: Methodological application of the spiral of silence theory. Public Opinion Quarterly 41: 143-158.

10. Victor D (2016) why you shouldn't trust "polls" conducted online. The NYT

11. Silver N (2016) Final election update: There's A wide range of outcomes, and most of them come up Clinton. FiveThirtyEight

12. Schmidt HC (2015) Student newspapers show opinion article political bias Newspaper Research Journal 36: 6-23.

13. Rappeport A (2016) Polls in crucial states show Donald Trump improving. The NYT

14. Johnson R, Pickup M (2008) Campaign trail heats as election forecasts: Measurements error and bias in 2004 presidential campaign polls. International Journal of Forecasting 24: 272-284.

15. Andreas G (2014) Accuracy of vote expectation survey in forecasting elections. Public Opinion Quarterly 78: 204-232.

16. Cox A and Katz J (2016) Presidential forecast Post-Mortem. The Upshot, The New York Times

17. Hartig H, Lapinski J and Psyllos S (2016) Poll: Clinton maintains national lead over Trump despite FBI letter. NBC news.

18. Barbaro M (2016) How the polling let us down. The New York Times.

19. Tamman M, Faulconbridge G (2016) How the polls, including ours, missed Trump's victory. Reuters, Politics, The New York Times.

20. Saad L (2016) Trump leads Clinton on top-ranking economic issues.

21. Chris Alcantara, Aaron Steckelberg, Darla Cameron, Tim Meko (2016) Where polling underestimated Trump's chances. The Washington Post.

22. Sides $\mathrm{J}$ (2016) which was the most accurate national poll in the 2016 presidential election? Monkey Cage - Analysis. 